\title{
UK Renal Registry 14th Annual Report: Chapter 4 Comorbidities and Current Smoking Status amongst Patients starting Renal Replacement Therapy in England, Wales and Northern Ireland from 2009 to 2010
}

\author{
Catriona Shaw ${ }^{\mathrm{a}}$, Lynsey Webb ${ }^{\mathrm{a}}$, Anna Casula ${ }^{\mathrm{a}}$, Charles R V Tomson ${ }^{\mathrm{b}}$

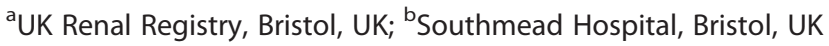

\section{Key Words}

Comorbidity · Diabetes - Dialysis · eGFR - Ethnicity · Haemoglobin · Mortality - Renal replacement therapy · Smoking · Survival analysis

\begin{abstract}
Introduction: Comorbidities are an important determinant of survival for patients requiring renal replacement therapy (RRT) and influence other care processes such as dialysis access formation and transplant wait-listing. The prevalence of comorbidities in incident RRT patients changes with age and varies between ethnic groups. This study describes these associations and the independent effect of comorbidities on outcomes. Methods: Incident patients reported to the UK Renal Registry (UKRR) with comorbidity data in 2009 and $2010(n=6,130)$ were included in analyses exploring the association of comorbidities with patient demographics, treatment modality, haemoglobin and renal function at start of RRT. For analyses examining association between comorbidities and survival, adult
\end{abstract}

patients starting RRT between 2005 and 2010 in centres reporting to the UKRR with comorbidity data $(n=17,184)$ were included. The relationship between comorbidities and mortality at 90 days and one year after 90 days from start of RRT were explored using Cox regression. Results: Completeness of comorbidity data was $49.1 \%$ in 2010 compared with $48.9 \%$ in 2005. Of patients with data, $55.4 \%$ had one or more comorbidities. Diabetes mellitus and ischaemic heart disease were the most common conditions, observed in $33.3 \%$ and $21.1 \%$ of patients respectively. $13.2 \%$ of incident RRT patients in the 2-year period were recorded as current smokers. The prevalence of comorbidity increased with increasing age across all ethnic groups. In multivariable survival analysis, malignancy and the presence of ischaemic/neuropathic ulcers were strong independent predictors of poor survival at 1 year after 90 days from the start of RRT in patients $<65$ years. Conclusion: Differences in prevalence rates of comorbid illnesses in incident RRT patients may reflect variation in access to health care or competing risk prior to commencing treatment. The generalisability of these analyses continues to be limited by poor data completeness.

$\begin{array}{ll}\text { KARGER } & \text { C 2012 S. Karger AG, Basel } \\ \text { Fax +4161306 1234 } & \text { 1160-2110/12/1205-0081\$38.00/0 } \\ \begin{array}{l}\text { E-Mail karger@karger.ch } \\ \text { www.karger.com }\end{array} & \begin{array}{l}\text { Accessible online at: } \\ \text { www.karger.com/nec }\end{array}\end{array}$

Catriona Shaw

UK Renal Registry, Southmead Hospital, Southmead Road, Bristol, BS10 5NB, UK

Email: renalregistry@renalregistry.nhs.uk 


\section{Introduction}

The importance of adjusting for comorbidity when undertaking centre [1-3] and international survival comparisons [4] is well recognised. As with all observational data, registry analyses exploring epidemiological issues, including access to treatments or survival analyses, are subject to a number of potential selection biases and confounding factors. Such registry analyses can be significantly strengthened by adjustment for casemix as differences in patient populations that exist across centres may influence both process and outcome measures. However an important consideration in applying case-mix adjustment to analyses is data completeness. If individuals with comorbidity data differ systematically from those without data, entering variables into statistical models can further bias outcome measures and provide invalid associations $[5,6]$.

The aim of this work is to describe the completeness of comorbidity data submitted to the UK Renal Registry (UKRR), the prevalence of comorbid conditions and current smoking status in incident renal replacement therapy (RRT) patients reported to the UKRR and to examine the association between these comorbidities and early mortality.

\section{Methods}

\section{Study population}

Incident adult ( $\geqslant 18$ years) RRT patients during 2009 and 2010 in the centres submitting data to the UKRR were considered. Of these, patients who had data recorded on comorbid conditions were included in statistical analyses. Data on completeness of comorbidity returns from each centre and overall may differ from those in previous UKRR reports due to some centres retrospectively entering previously missing comorbidity data.

\section{Centre exclusions}

The nine centres in Scotland do not provide comorbidity data to the UKRR and are not included in these analyses. There was concern that data extraction in two centres (Stoke and Colchester) was inaccurate and these centres were excluded from this year's comorbidity analyses.

Definition of comorbidity and method of data collection

Clinical staff in each centre are responsible for recording in yes/ no format the presence or absence of 13 comorbid conditions and information on current tobacco smoking (table 4.1) for each patient at the time of starting RRT on their renal information technology (IT) system. Definitions of each of these conditions are given in appendix B (www.renalreg.com/report-area/report 2011/appendix-B.pdf).
Table 4.1. Comorbid conditions listed in the UKRR dataset

Comorbidity

- Angina

- Previous myocardial infarction (MI) within 3 months prior to start of RRT

- Previous MI more than 3 months prior to start of RRT

- Previous coronary artery bypass graft (CABG) or coronary angioplasty

(in some analyses the above four variables are combined under the term 'ischaemic heart disease')

- Cerebrovascular disease

- Diabetes (when not listed as the primary renal disease)

- Chronic obstructive pulmonary disease (COPD)

- Liver disease

- Claudication

- Ischaemic or neuropathic ulcers

- Non-coronary angioplasty, vascular graft, or aneurysm

- Amputation for peripheral vascular disease (in some analyses these four variables are combined under the term 'peripheral vascular disease')

- Smoking

- Malignancy

Patients were classified as having complete comorbidity data if there was at least one entry (yes/no) for any one or more of the comorbid conditions. Comorbidities were grouped into broader categories for some analyses:

- 'Ischaemic heart disease' was defined as the presence of one or more of the following conditions: angina, myocardial infarction (MI) in the three months prior to starting RRT, MI more than three months prior to starting RRT or coronary artery bypass grafting (CABG)/angioplasty.

- 'Peripheral vascular disease' was defined as the presence of one or more of the following conditions: claudication, ischaemic or neuropathic ulcers, non-coronary angioplasty, vascular graft, aneurysm or amputation for peripheral vascular disease.

- 'Non-coronary vascular disease' was defined as the presence of cerebrovascular disease or any of the data items that comprise 'peripheral vascular disease'.

Specific consideration needs to be made regarding diabetes coding. The UKRR also collect data on Primary Renal Diagnosis (PRD), and have used these data alongside the comorbidity data to determine which people had diabetes mellitus. The comorbidity screen is intended to capture those patients who have diabetes only when it is not the PRD, however some clinicians do enter 'yes' in the comorbidity field in such cases. Prior to statistical analyses, we examine these fields together to identify these cases and ensure diabetes is only counted as either the PRD or a comorbid condition for a certain individual.

\section{Ethnicity data reporting}

Some centres electronically upload ethnicity coding to their renal IT system from the hospital Patient Administration Systems (PAS) [7]. Ethnicity coding in PAS is based on self-reported 
ethnicity and uses a different system [8] to the remaining centres where coding of ethnicity is performed by clinical staff and recorded directly into the renal IT system (using a variety of coding systems). For all these analyses, data on ethnic origin were grouped into Whites, South Asians, Blacks and Others. Appendix $\mathrm{H}$ details the regrouping of the PAS codes into the above ethnic categories.

\section{Statistical methods}

The statistical methods for the three individual sections of this chapter are described separately.

\section{1) Patient demographics}

The proportion of patients starting RRT with various comorbidities was examined by age group (18-34, 35-44, 45-54, $55-64,65-74$ and $\geqslant 75$ years), primary renal disease, ethnic origin and first modality of RRT. Chi-squared, Fischer's exact and Kruskal-Wallis tests were used as appropriate to test for statistically significant differences between groups.

\section{2) Late presentation (referral) and start of $R R T$}

Referral time was defined as the number of days between the date first seen by a nephrologist and the date of starting RRT. Referral times of more than 90 days and less than 90 days define early and late presentation, respectively. Data on referral time were incomplete and therefore only patients with data on comorbidity and referral time from centres with $>75 \%$ data completeness for referral time were included in this analysis. Many UKRR analyses, including those presented here, rely on the accuracy of the date of start of RRT. A discussion of the issues around definition of the start date is included in chapter 13 of the 2009 Report [9].

\section{3) Patient survival}

The Registry collected data with a 'timeline' entry on all patients who had started RRT for Established Renal Failure (ERF). Patients presenting acutely and initially classified as acute renal failure requiring dialysis who continue to require long-term dialysis, can subsequently be re-classified by clinicians as having had ERF from the date of their first RRT. The death rate is high in the first 90 days of commencing RRT with variability observed between centres. This between centre variation may in part be due to clinician variation in the classification of patients who present acutely requiring RRT and who may be deemed from the start to be unlikely to recover renal function. As mortality rate varies with time on RRT and to remove the influence of between centre variation in the classification of patients, the survival analysis was stratified into two time frames. This also enables comparison with results from other national registries. The association of comorbid conditions and survival within the first 90 days was analysed and subsequently the association of comorbid conditions and 1 year survival in the cohort who survived after 90 days from the start of RRT was also analysed.

For each of the follow up periods, the association of baseline comorbidity with survival was analysed using univariable and multivariable Cox regression models. For analyses of survival within the first 90 days, the cohort included patients starting RRT between 1st January 2005 and 30th September 2010 to allow a minimum of three months follow-up from the start of RRT. For the 1 year survival analyses in individuals who survived at least 90 days after the start of RRT, the cohort data on individuals who started RRT between 1st January 2005 and 30th September 2009.

For each variable, the models were used to estimate the hazard ratio of death, comparing the survival experience of patients with a particular comorbidity with those who did not have the comorbidity (reference group). For both the univariable and multivariable Cox models, patients were first stratified by age group ( $<65$ years and $\geqslant 65$ years) to account for the increasing incidence of certain comorbidities with age, which may otherwise confound the analyses. The multivariable models used an automatic selection procedure to identify the variables most strongly related to survival. The potential variables to be included were: age (per 10 year increase), smoking status, diabetes (listed as PRD or not listed as PRD) and the other 12 comorbidities listed in table 4.1 . The automatic procedure starts by including only the variable most strongly related to survival. Then, with that variable included, it fits models adding each of the remaining variables in turn (singly) and chooses the variable that adds most to the model (in addition to the contribution made by the first variable included). The process continues in this way, adding variables that make a further significant contribution to the model, and removing any whose contribution becomes non-significant once other variables have been added. The final model only includes those variables selected by the process. These automatic methods have been used to give an indication of the variables most strongly related to survival but caution is needed in interpreting them because, amongst other things, when using correlated variables, a slight difference in the data (or in the algorithm chosen) could result in different variables being included in the final models. A more robust analysis would make a considered judgement of which variables should be included (rather than an automatic one) and may require additional interaction terms.

For each model, a $\mathrm{R}^{2}$ value was calculated using the Royston and Sauerbrei method [10]. The $\mathrm{R}^{2}$ value is the percentage of the variation in mortality which is explained by the variables included in the final model.

All statistical analyses were performed using SAS version 9.2.

\section{Results}

\section{Completeness of comorbidity returns from each participating centre}

The number of patients with data on comorbidity and other variables included in the analyses are summarised in figure 4.1.

Of 12,434 incident RRT patients in 2009 and 2010, 6,130 individuals $(49.3 \%)$ had data on comorbidity reported. In 2010, 6,154 patients commenced RRT in centres in England, Wales and Northern Ireland. Comorbidity data were provided for 3,024 (49.1\%) of those patients (tables 4.2, 4.3). Table 4.2 highlights the continued wide variation in the completeness of data returns with 4 centres providing data on $100 \%$ of 


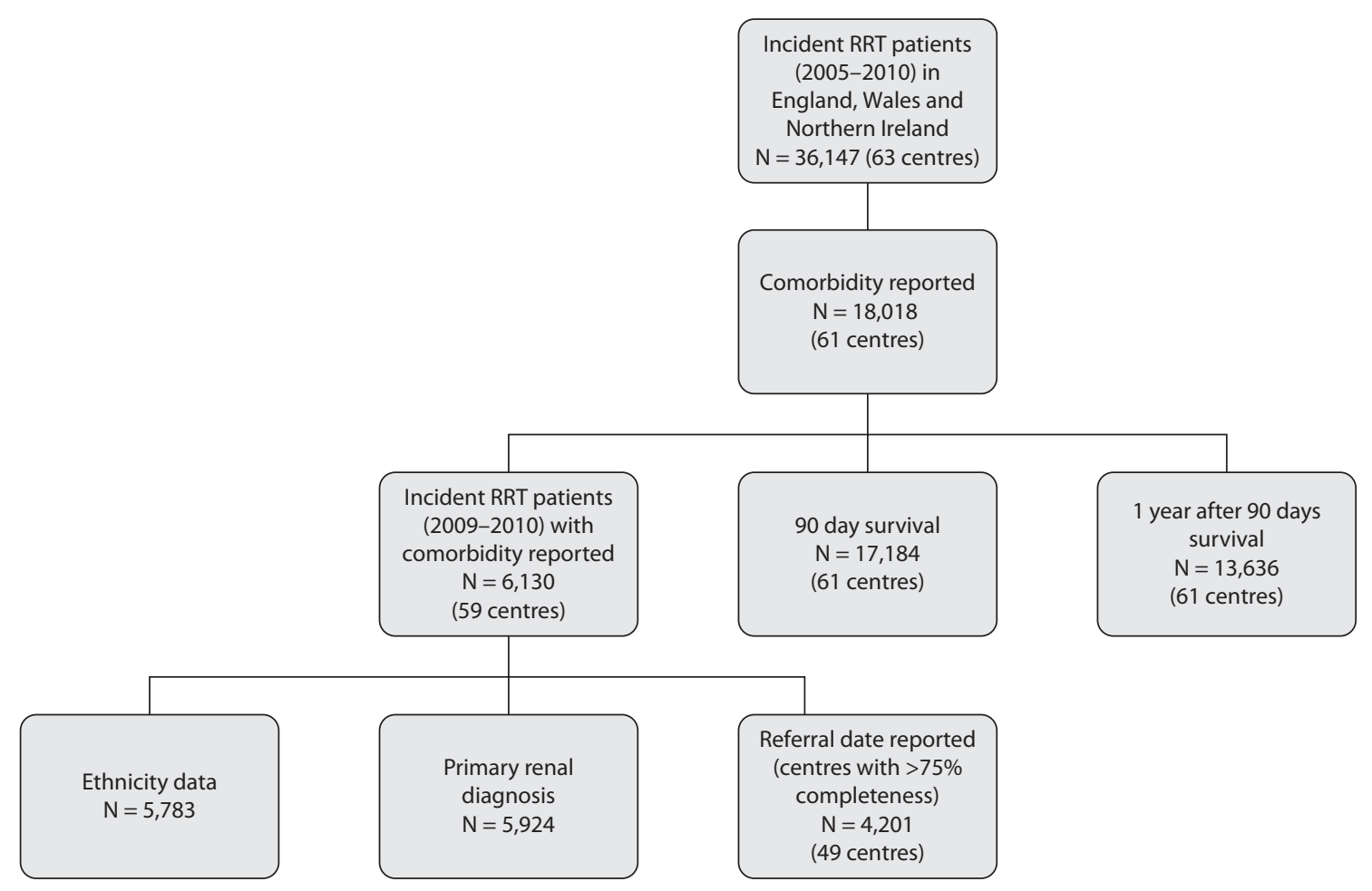

Fig. 4.1. Flow chart showing number of patients included in the various analyses

patients, but 15 centres providing data for less than $5 \%$ of new patients in 2010 .

Limiting the comparison to the centres that reported in 2005, data completeness for comorbidity has remained roughly the same. Completeness was $48.9 \%$ in 2005 and $49.1 \%$ in 2010 (table 4.3). When centres with $0 \%$ completeness for comorbidity were excluded, the median percentage of comorbidity returns in 2010 was $72.0 \%$. For centres returning comorbidity data there has been an annual improvement since 2005 (table 4.3). This could suggest that once renal information systems are set up to return comorbidity information, it is possible to improve data completeness.

\section{Prevalence of multiple comorbidity}

Including all incident patients from the years 2009 $2010(\mathrm{n}=12,434)$, comorbidity data were available for $6,130(49.3 \%)$. More than half of these patients had one or more comorbidities (55.4\%) (table 4.4), but in the subgroup of patients aged $\geqslant 65$ years, $67.6 \%$ had one or more comorbidities (table 4.5).

\section{Frequency of each comorbid condition}

Table 4.5 lists the prevalence of specific comorbidities and the percentage of the total number of incident patients for whom data was available for that item.
Diabetes mellitus (either listed as the cause of PRD or as a comorbidity) was present in $32.7 \%$ of all patients. This is different to the sum of diabetes (not listed as PRD) and diabetes listed as PRD in Table 4.5 and reflects some patients having both an entry in the comorbidity field for diabetes and having it recorded as their PRD as described in the methods section.

\section{Prevalence of comorbidity by age band}

Ischaemic heart disease, cerebrovascular disease, COPD, claudication and malignancy were more prevalent in patients 65 years and over. Liver disease, ischaemic/neuropathic ulcers and prior amputation were more frequently observed in younger patients; actual percentages, nevertheless, were quite small (table 4.5). Smoking was also more common amongst patients under 65 years. With age categorised in 10 year age groups, prevalence of most comorbidities is seen to increase markedly from 18-65 years and appeared to plateau beyond this (figures 4.2, 4.3). In those patients aged $>75$ years there was a slight reduction of most reported comorbidities.

Prevalence of comorbidity by ethnic origin

Figures 4.4 and 4.5 illustrate the presence of comorbidity by ethnic origin and age group. Figure 4.4 shows a 
Table 4.2. Completeness of comorbidity data returns on incident patients from individual renal centres 2005-2010

\begin{tabular}{|c|c|c|c|c|c|c|c|c|c|c|c|c|}
\hline Centre & \multicolumn{2}{|c|}{2005} & \multicolumn{2}{|c|}{2006} & \multicolumn{2}{|c|}{2007} & \multicolumn{2}{|c|}{2008} & \multicolumn{2}{|c|}{2009} & \multicolumn{2}{|c|}{2010} \\
\hline B Heart & 119 & 5 & 116 & 3 & 101 & 6 & 105 & 10 & 99 & 49 & 95 & 74 \\
\hline $\mathrm{B} \mathrm{QEH}$ & 199 & 1 & 186 & 1 & 225 & 2 & 268 & 1 & 255 & 3 & 197 & 0 \\
\hline Bangor & 40 & 50 & 42 & 60 & 36 & 69 & 41 & 68 & 30 & 83 & 26 & 96 \\
\hline Bradfd & 67 & 96 & 50 & 98 & 88 & 100 & 63 & 90 & 61 & 90 & 64 & 92 \\
\hline Brightn & 112 & 14 & 131 & 24 & 120 & 37 & 121 & 34 & 120 & 12 & 107 & 6 \\
\hline Bristol & 175 & 81 & 176 & 98 & 156 & 83 & 176 & 77 & 158 & 85 & 169 & 92 \\
\hline Camb & 111 & 3 & 156 & 3 & 128 & 2 & 109 & 0 & 136 & 3 & 108 & 1 \\
\hline Cardff & 184 & 22 & 206 & 7 & 221 & 5 & 150 & 5 & 179 & 9 & 188 & 16 \\
\hline Carlis & 31 & 94 & 27 & 93 & 26 & 92 & 30 & 97 & 24 & 88 & 21 & 62 \\
\hline Covnt & 84 & 0 & 104 & 2 & 113 & 0 & 116 & 0 & 118 & 0 & 118 & 1 \\
\hline Derby & 71 & 76 & 70 & 71 & 63 & 86 & 96 & 92 & 78 & 94 & 80 & 85 \\
\hline Derry & & & 4 & 75 & 8 & 63 & 6 & 50 & 17 & 71 & 18 & 72 \\
\hline Donc & & & & & 20 & 90 & 26 & 27 & 40 & 43 & 44 & 61 \\
\hline Dorset & 49 & 88 & 53 & 92 & 65 & 89 & 85 & 85 & 76 & 78 & 72 & 65 \\
\hline Dudley & 38 & 0 & 45 & 2 & 40 & 0 & 46 & 0 & 69 & 0 & 41 & 0 \\
\hline Exeter & 111 & 29 & 105 & 30 & 126 & 8 & 135 & 4 & 145 & 1 & 136 & 4 \\
\hline Glouc & 61 & 97 & 74 & 89 & 58 & 97 & 47 & 87 & 79 & 67 & 58 & 43 \\
\hline Hull & 125 & 98 & 105 & 91 & 99 & 98 & 113 & 91 & 101 & 76 & 88 & 84 \\
\hline Ipswi & 59 & 29 & 42 & 62 & 40 & 50 & 38 & 34 & 38 & 8 & 34 & 9 \\
\hline Kent & & & & & 172 & 75 & 140 & 79 & 131 & 89 & 134 & 100 \\
\hline L Barts & 187 & 90 & 190 & 83 & 214 & 84 & 206 & 80 & 239 & 86 & 207 & 72 \\
\hline Liv Ain & 29 & 41 & 35 & 54 & 36 & 44 & 42 & 67 & 38 & 71 & 49 & 4 \\
\hline Liv RI & 139 & 63 & 141 & 52 & 112 & 56 & 102 & 42 & 110 & 45 & 102 & 21 \\
\hline M Hope & 110 & 33 & 132 & 12 & 121 & 12 & 142 & 1 & 125 & 0 & 146 & 0 \\
\hline M RI & & & & & 160 & 33 & 133 & 41 & 147 & 64 & 163 & 40 \\
\hline Middlbr & 84 & 90 & 108 & 77 & 99 & 79 & 93 & 92 & 95 & 92 & 98 & 96 \\
\hline Newc & 112 & 17 & 106 & 16 & 106 & 22 & 97 & 21 & 100 & 23 & 95 & 52 \\
\hline Newry & 28 & 14 & 13 & 23 & 15 & 27 & 21 & 90 & 20 & 100 & 21 & 95 \\
\hline Norwch & 119 & 10 & 113 & 12 & 110 & 18 & 90 & 20 & 73 & 23 & 85 & 39 \\
\hline Nottm & 145 & 99 & 137 & 97 & 130 & 93 & 115 & 89 & 134 & 97 & 113 & 96 \\
\hline Oxford & 153 & 51 & 157 & 24 & 144 & 87 & 150 & 81 & 177 & 91 & 167 & 95 \\
\hline Plymth & 60 & 45 & 92 & 66 & 76 & 79 & 69 & 70 & 56 & 82 & 55 & 73 \\
\hline Ports & 149 & 64 & 175 & 64 & 157 & 69 & 170 & 58 & 149 & 62 & 150 & 45 \\
\hline Prestn & 121 & 29 & 121 & 33 & 132 & 43 & 112 & 42 & 147 & 50 & 122 & 46 \\
\hline Redng & 90 & 3 & 88 & 3 & 94 & 6 & 105 & 3 & 99 & 3 & 89 & 0 \\
\hline Sheff & 158 & 43 & 168 & 58 & 165 & 57 & 180 & 52 & 150 & 53 & 144 & 78 \\
\hline Shrew & 41 & 59 & 55 & 65 & 58 & 66 & 61 & 87 & 47 & 87 & 58 & 100 \\
\hline Stevng & 89 & 48 & 122 & 53 & 89 & 73 & 103 & 77 & 98 & 95 & 110 & 98 \\
\hline Sthend & 34 & 71 & 48 & 83 & 34 & 88 & 36 & 81 & 23 & 96 & 30 & 70 \\
\hline Stoke & & & & & 87 & 0 & 81 & 0 & 110 & 0 & 93 & 0 \\
\hline Sund & 60 & 93 & 57 & 93 & 62 & 100 & 45 & 98 & 64 & 98 & 55 & 78 \\
\hline
\end{tabular}


Table 4.2. Continued

\begin{tabular}{|c|c|c|c|c|c|c|c|c|c|c|c|c|}
\hline \multirow[b]{2}{*}{ Centre } & \multicolumn{2}{|c|}{2005} & \multicolumn{2}{|c|}{2006} & \multicolumn{2}{|c|}{2007} & \multicolumn{2}{|c|}{2008} & \multicolumn{2}{|c|}{2009} & \multicolumn{2}{|c|}{2010} \\
\hline & $\mathrm{N}$ & $\%$ return & $\mathrm{N}$ & $\%$ return & $\mathrm{N}$ & $\%$ return & $\mathrm{N}$ & $\%$ return & $\mathrm{N}$ & $\%$ return & $\mathrm{N}$ & $\%$ return \\
\hline Swanse & 101 & 97 & 116 & 97 & 127 & 97 & 124 & 96 & 116 & 97 & 135 & 79 \\
\hline Truro & 32 & 84 & 52 & 77 & 45 & 91 & 41 & 37 & 58 & 64 & 43 & 67 \\
\hline Tyrone & 24 & 42 & 29 & 59 & 21 & 81 & 25 & 72 & 19 & 89 & 10 & 100 \\
\hline Ulster & 9 & 56 & 8 & 63 & 16 & 100 & 14 & 100 & 13 & 100 & 20 & 95 \\
\hline Wirral & 60 & 7 & 52 & 0 & 53 & 0 & 39 & 3 & 63 & 2 & 52 & 0 \\
\hline Wolve & 95 & 84 & 85 & 88 & 68 & 93 & 88 & 95 & 65 & 100 & 107 & 93 \\
\hline Wrexm & 42 & 38 & 26 & 58 & 27 & 63 & 21 & 76 & 20 & 90 & 24 & 100 \\
\hline York & 46 & 89 & 48 & 90 & 38 & 84 & 38 & 79 & 47 & 68 & 36 & 92 \\
\hline Totals & 5,517 & & 5,807 & & 6,151 & & 6,238 & & 6,280 & & 6,154 & \\
\hline
\end{tabular}

Blank cells - no data returned to the UKRR for that year

Table 4.3. Summary of completeness of incident patient comorbidity returns (2005-2010)

\begin{tabular}{|c|c|c|c|c|c|c|c|}
\hline & \multicolumn{6}{|c|}{ Years } & \multirow{2}{*}{$\begin{array}{c}\text { Combined } \\
\text { years }\end{array}$} \\
\hline & 2005 & 2006 & 2007 & 2008 & 2009 & 2010 & \\
\hline Number of renal centres included & 56 & 57 & 62 & 63 & 63 & 63 & \\
\hline Total number of new patients & 5,517 & 5,807 & 6,151 & 6,238 & 6,280 & 6,154 & 36,147 \\
\hline Number of patients with comorbidity data entries & 2,699 & 2,838 & 3,195 & 3,156 & 3,106 & 3,024 & 18,018 \\
\hline Percentage of patients with comorbidity data entries & 48.9 & 48.9 & 51.9 & 50.6 & 49.5 & 49.1 & 49.8 \\
\hline Percentage restricted to centres in since 2005 & 48.9 & 48.9 & 52.2 & 51.1 & 49.1 & 49.1 & 49.9 \\
\hline Median percentage amongst only centres returning $>0 \%$ comorbidity & 50.5 & 59.3 & 69.4 & 69.8 & 70.6 & 72.0 & 65.5 \\
\hline
\end{tabular}

higher prevalence of having at least one comorbidity recorded amongst patients of White origin compared to incident patients from an ethnic minority. Figure 4.5 shows that this pattern is observed across all age groups. However, diabetes mellitus specifically is much more frequently reported in South Asian patients (48.1\%) than in White individuals (30.0\%) (table 4.6). The reported prevalence of smoking was highest in individuals of White ethnicity (14.8\%).

\section{Prevalence of comorbidity amongst patients with diabetes mellitus}

Table 4.7 describes comorbidity amongst patients with

Table 4.4. Number of reported comorbidities in patients starting RRT, as a percentage of those for whom comorbidity data were available 2009-2010

\begin{tabular}{lcccccc}
\hline $\begin{array}{l}\text { Number of } \\
\text { comorbidities }\end{array}$ & 0 & 1 & 2 & 3 & 4 & $5+$ \\
\hline Percentage & 44.6 & 28.6 & 13.6 & 7.7 & 3.2 & 2.4 \\
\hline
\end{tabular}

and without diabetes (as either primary renal disease or comorbidity). As would be expected, patients with diabetes mellitus had higher prevalence of peripheral vascular disease $(20.3 \%$ compared to $7.5 \%$ in nondiabetics). Similarly, ischaemic heart disease and cerebrovascular disease were more common in diabetics. Similar proportions of diabetic and non-diabetic patients were smokers at the time of initiation of RRT (13.3\% and $13.0 \%$ respectively). Malignancy was more common in non-diabetic patients $(\mathrm{p}<0.0001)$ and may reflect "competing risks", with diabetics tending to die at a younger age with cardiovascular disease, rather than developing malignancy in older age.

\section{Late presentation and comorbidity}

Table 4.8 shows the referral time for patients with various comorbidities. In total, 4,201 individuals contributed data to this analysis. Patients referred to a nephrologist early had a higher prevalence of peripheral vascular disease, cerebrovascular disease and ischaemic heart disease. There were a higher proportion of patients with malignancy in the late referral group. 
Table 4.5. Frequency with which each condition was reported in incident RRT patients 2009-2010

\begin{tabular}{|c|c|c|c|c|c|c|}
\hline Comorbidity & \multicolumn{2}{|c|}{ Age $<65$ years } & \multicolumn{2}{|c|}{ Age $\geqslant 65$ years } & $\mathrm{p}$ value $^{*}$ & $\begin{array}{l}\% \text { overall } \\
\text { prevalence }\end{array}$ \\
\hline Angina & 207 & $(6.8)$ & 538 & $(18.0)$ & $<0.0001$ & 12.3 \\
\hline MI in past 3 months & 49 & $(1.6)$ & 91 & $(3.0)$ & 0.0002 & 2.3 \\
\hline MI >3 months ago & 170 & $(5.6)$ & 453 & $(15.1)$ & $<0.0001$ & 10.3 \\
\hline Diabetes (not listed as PRD) & 183 & $(6.0)$ & 385 & $(12.8)$ & $<0.0001$ & 9.4 \\
\hline Diabetes listed as PRD & 824 & $(27.4)$ & 612 & $(20.5)$ & $<0.0001$ & 23.9 \\
\hline COPD & 148 & $(4.9)$ & 302 & $(10.1)$ & $<0.0001$ & 7.4 \\
\hline Liver disease & 114 & $(3.7)$ & 53 & $(1.8)$ & $<0.0001$ & 2.8 \\
\hline Claudication & 129 & $(4.2)$ & 256 & $(8.6)$ & $<0.0001$ & 6.4 \\
\hline Ischaemic/neuropathic ulcers & 120 & $(3.9)$ & 94 & (3.1) & 0.0917 & 3.5 \\
\hline
\end{tabular}

${ }^{*} \mathrm{p}$ values from Chi-squared tests for differences between age groups in the percentage with the comorbidity

Age and comorbidity in patients by treatment modality at start of RRT

All comorbidities were more prevalent in patients receiving haemodialysis as their initial modality of treatment than in those starting on peritoneal dialysis (table 4.9). The median age for all patients starting dialysis in England, Wales and N. Ireland in 2009-2010 67.9 years (IQR 55.1-76.6 years) for haemodialysis and 58.4 years (IQR 45.1-69.3 years) for peritoneal dialysis. In comparison, the median age of patients with comorbidity data starting RRT on HD was 67 years compared

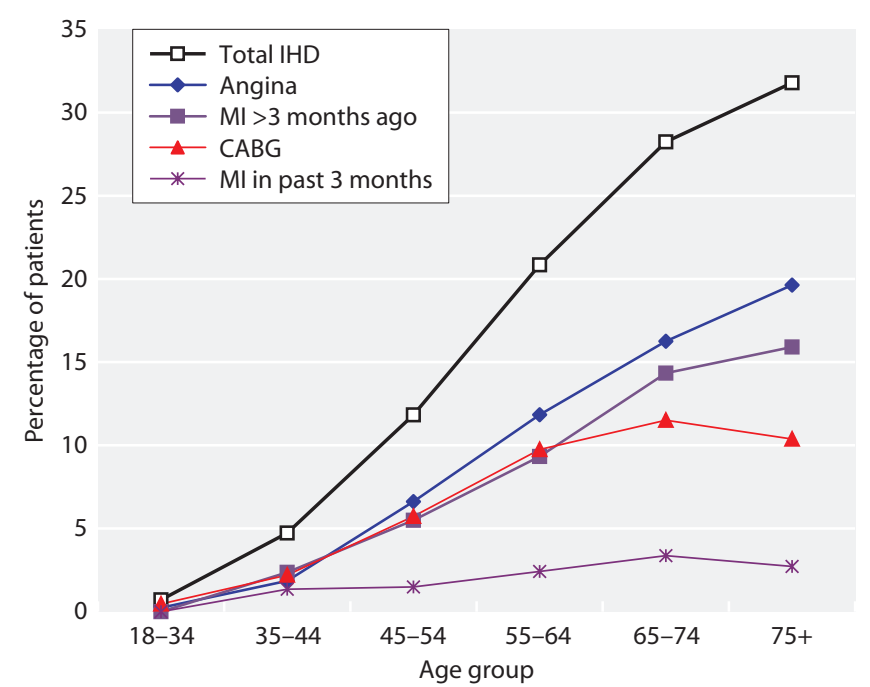

Fig. 4.2. Prevalence of ischaemic heart disease amongst incident patients 2009-2010 by age at start of RRT with 59 years for those starting on PD (Kruskal Wallis test, $\mathrm{p}<0.0001)$.

For each of the comorbid conditions, the median age of patients on HD was higher than for patients on $\mathrm{PD}$ (table 4.9).

\section{Comorbidity and survival within 90 days of starting RRT}

On univariable analysis stratified by age, most comorbidity was associated with an increased risk of death in the first 90 days after starting RRT when

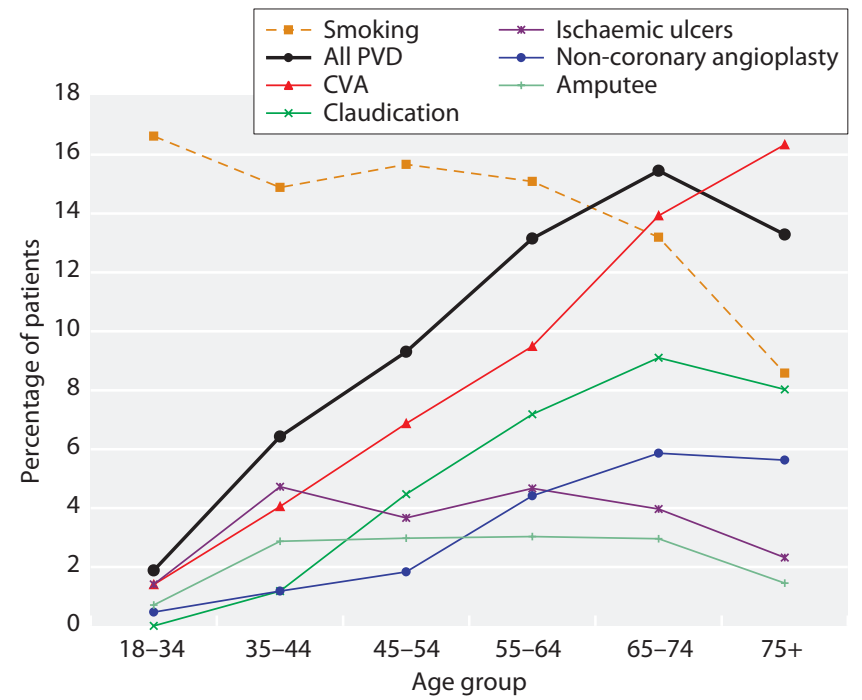

Fig. 4.3. Prevalence of non-coronary vascular disease amongst incident patients $2009-2010$ by age at start of RRT

Nephron Clin Pract 2012;120(suppl 1):c81-c91 


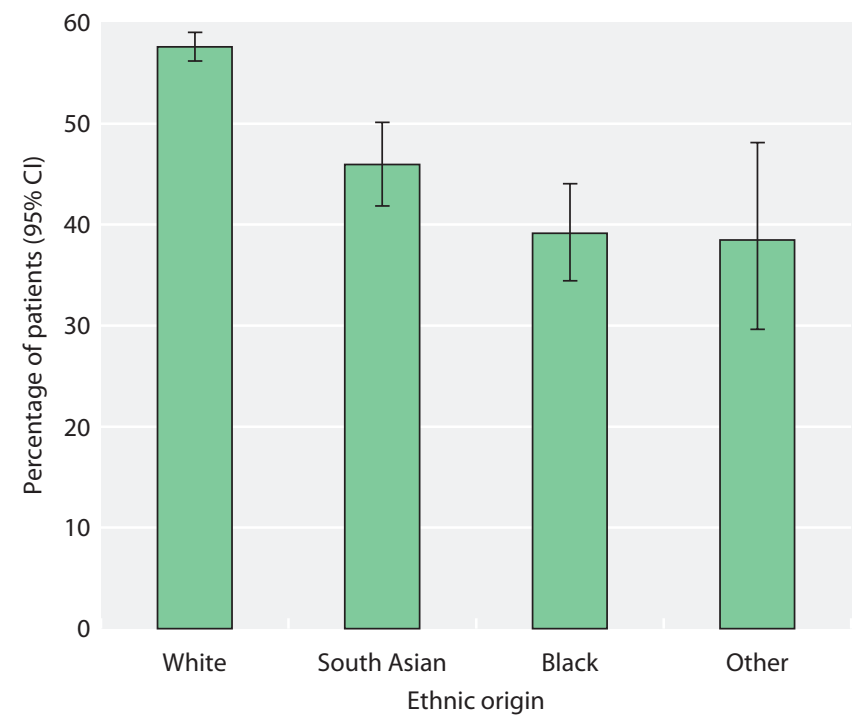

Fig. 4.4. Presence of comorbid conditions at the start of RRT by ethnic origin amongst patients starting RRT 2009-2010

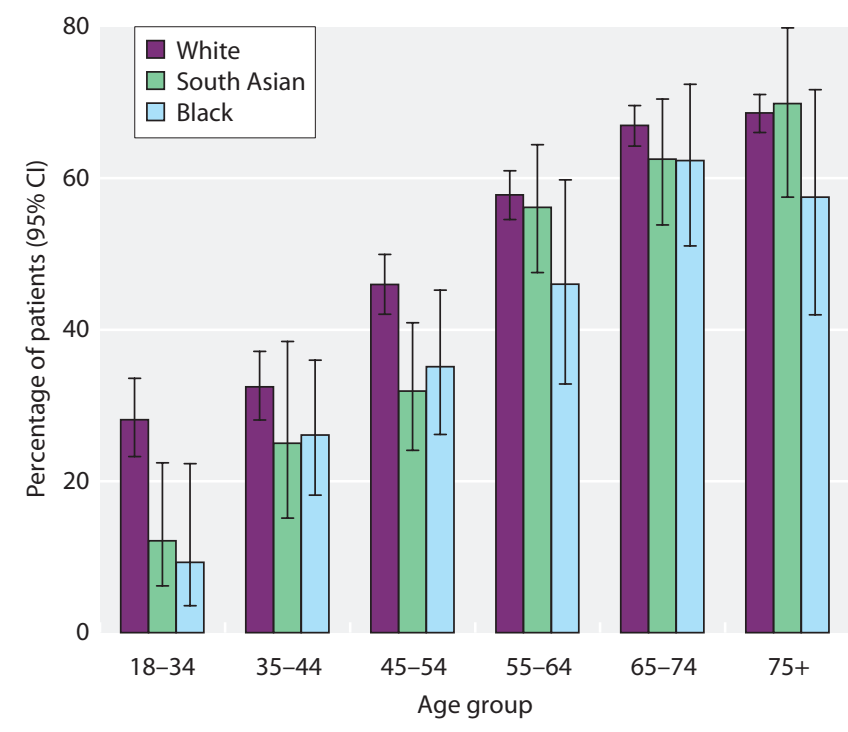

Fig. 4.5. Percentage of patients with comorbidity by ethnic origin in each age group at the start of RRT 2009-2010

Table 4.6. Prevalence of comorbidities amongst incident patients starting RRT 2009-2010 by ethnic group, as percentages of the total number of patients in that ethnic group for whom comorbidity data was available

\begin{tabular}{|c|c|c|c|c|c|c|c|c|c|}
\hline Ischaemic heart disease & \multicolumn{9}{|c|}{ Number of patients (\%) with comorbidity } \\
\hline Cerebrovascular disease & 516 & $(11.0)$ & 52 & $(9.6)$ & 48 & $(12.3)$ & 7 & $(6.7)$ & 0.30 \\
\hline Diabetes (not listed as PRD) & 426 & $(9.1)$ & 54 & $(9.9)$ & 27 & $(6.9)$ & 6 & $(5.8)$ & 0.26 \\
\hline Diabetes listed as PRD & 1,000 & $(21.6)$ & 209 & $(38.2)$ & 119 & $(30.2)$ & 22 & $(21.4)$ & $<0.0001$ \\
\hline Peripheral vascular disease & 584 & $(12.5)$ & 46 & $(8.6)$ & 31 & $(8.1)$ & 5 & $(4.8)$ & 0.001 \\
\hline Smoking & 639 & (14.2) & 42 & $(7.9)$ & 31 & $(8.2)$ & 12 & (11.8) & $<0.0001$ \\
\hline Malignancy & 692 & $(14.8)$ & 21 & $(3.9)$ & 24 & $(6.2)$ & 7 & $(6.7)$ & $<0.0001$ \\
\hline
\end{tabular}

${ }^{*} \mathrm{p}$ values from Chi-squared tests for differences between ethnic groups in the percentage with the comorbidities

Table 4.7. Number and percentage of patients with and without diabetes (either as primary diagnosis or comorbidity) who have other comorbid conditions

\begin{tabular}{|c|c|c|c|c|c|}
\hline \multirow[b]{2}{*}{ Comorbidity } & \multicolumn{2}{|c|}{ Non-diabetic patients } & \multicolumn{2}{|c|}{ Diabetic patients } & \multirow[b]{2}{*}{$\mathrm{p}$ value ${ }^{\star}$} \\
\hline & $\mathrm{N}$ & $(\%)$ & $\mathrm{N}$ & $(\%)$ & \\
\hline Ischaemic heart disease & 653 & $(16.8)$ & 581 & $(29.8)$ & $<0.0001$ \\
\hline Cerebrovascular disease & 342 & $(8.8)$ & 282 & $(14.5)$ & $<0.0001$ \\
\hline COPD & 291 & $(7.5)$ & 150 & $(7.7)$ & 0.77 \\
\hline Liver disease & 101 & $(2.6)$ & 52 & $(2.7)$ & 0.87 \\
\hline Peripheral vascular disease & 292 & $(7.5)$ & 393 & $(20.3)$ & $<0.0001$ \\
\hline Smoking & 487 & $(13.0)$ & 249 & $(13.3)$ & 0.74 \\
\hline Malignancy & 584 & $(15.0)$ & 184 & $(9.5)$ & $<0.0001$ \\
\hline
\end{tabular}

${ }^{*} \mathrm{p}$ values from Chi-squared tests for differences in the percentage with the comorbidities between diabetic patients and non-diabetic patients 
Table 4.8. Percentage prevalence of specific comorbidities amongst patients presenting late (0-89 days) compared with those presenting early (>89 days)

\begin{tabular}{|c|c|c|c|c|c|}
\hline \multirow[b]{2}{*}{ Comorbidity } & \multicolumn{2}{|c|}{ Late referral } & \multicolumn{2}{|c|}{ Early referral } & \multirow[b]{2}{*}{$\mathrm{p}$ value } \\
\hline & $\mathrm{N}$ & $(\%)$ & $\mathrm{N}$ & $(\%)$ & \\
\hline Ischaemic heart disease & 136 & $(16.9)$ & 769 & $(23.0)$ & 0.0002 \\
\hline Cerebrovascular disease & 51 & $(6.3)$ & 384 & $(11.5)$ & $<0.0001$ \\
\hline Diabetes (not listed as PRD) & 57 & $(7.0)$ & 315 & $(9.4)$ & 0.031 \\
\hline COPD & 61 & $(7.5)$ & 273 & $(8.1)$ & 0.6 \\
\hline Liver disease & 29 & $(3.6)$ & 86 & $(2.6)$ & 0.12 \\
\hline Peripheral vascular disease & 81 & $(10.0)$ & 414 & $(12.4)$ & 0.065 \\
\hline Malignancy & 161 & $(19.9)$ & 398 & $(11.9)$ & $<0.0001$ \\
\hline Smoking & 118 & $(15.2)$ & 415 & $(12.7)$ & 0.07 \\
\hline
\end{tabular}

${ }^{*} \mathrm{p}$ values from Chi-squared tests for differences between referral groups in the percentage with the comorbidities

compared with a patient in the same age group without that comorbidity. This was true amongst patients aged $<65$ years and those aged $\geqslant 65$ years, the associations being more profound for those aged $<65$ years (data not shown). Results of the multivariable stepwise Cox regression analyses stratified by age group $(<65$ and $\geqslant 65$ ) are shown in tables 4.10 and 4.11 . As identified in the univariable models, the relative magnitude of the hazard ratios associated with comorbidity in younger patients tended to be greater than in the older patient group. Diabetes did not emerge as an independent predictor of death, perhaps explained by its close association with, and mediation in the causal pathway by, cardiovascular diseases. Some comorbidities may appear not to be associated with an increased risk of death in this analysis because of the low number of patients in these groups or because of selection within the cohort. For example individuals with severe comorbid disease, and whose prognosis on RRT was considered very poor, may not have been started on RRT (for instance, liver disease in those aged $\geqslant 65$ years).

The final five variables in the model examining death within the first 90 days of starting RRT in patients aged $<65$ (table 4.10) explain $47 \%$ of the variation in survival. For patients aged $\geqslant 65$, the final eight variables in the model explain $15 \%$ of the variation in survival (table 4.11).

\section{Comorbidity and survival 1 year after 90 days of commencing $R R T$}

Age, smoking and five comorbidities were independently associated with an increased hazard of death within the first year after 90 days of commencing RRT for patients aged $<65$ years and four of these (age,

Table 4.9. Number (and percentage) of incident patients with comorbid conditions starting PD and HD 2009-2010

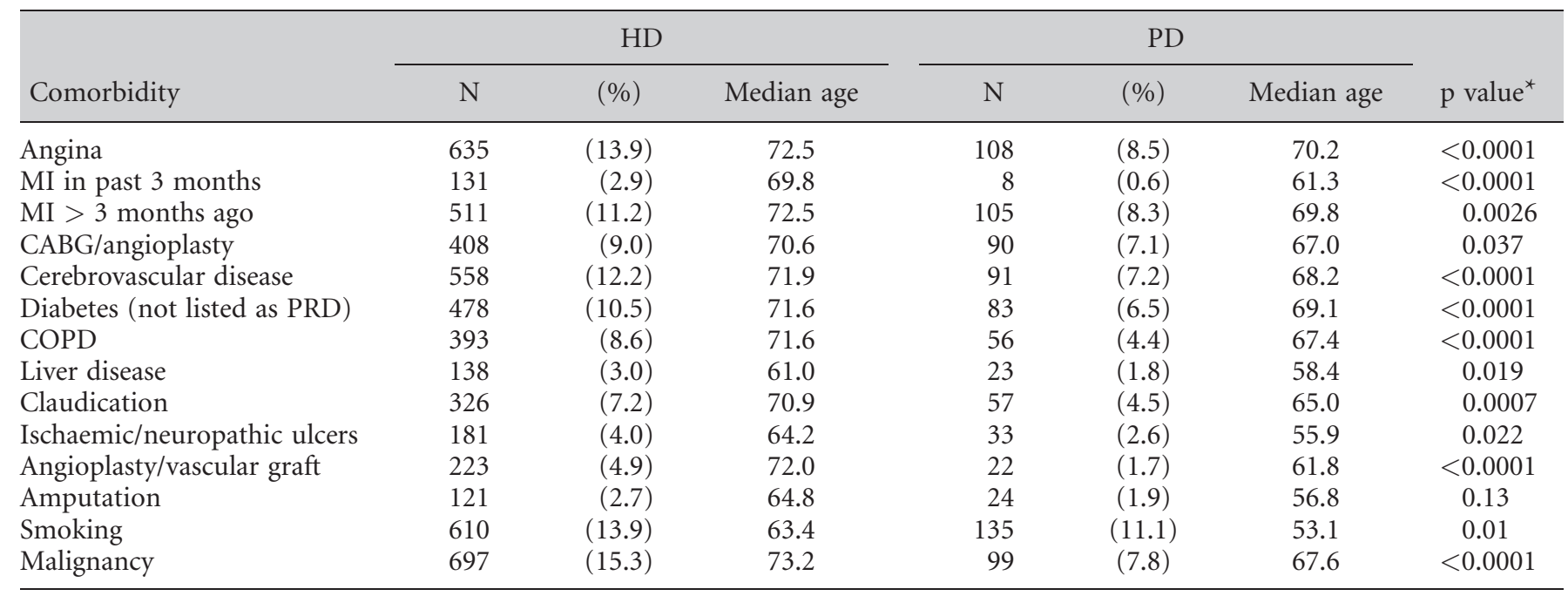

${ }^{*} \mathrm{p}$ values from Chi-squared tests for differences between modalities in the percentage with the comorbidities 
Table 4.10. Multivariate Cox proportional hazards model ${ }^{\star}$ for predictors of death within the first 90 days of starting RRT during 01/01/2005-30/09/2010: patients aged $<65$ years

\begin{tabular}{lccc}
\hline Comorbidity & Hazard ratio & $95 \%$ CI & p value \\
\hline Malignancy & 3.9 & $2.6-6.0$ & $<0.0001$ \\
Claudication & 2.6 & $1.5-4.4$ & 0.001 \\
Liver disease & 2.1 & $1.1-4.0$ & 0.026 \\
Angina & 1.8 & $1.1-2.9$ & 0.013 \\
Age (per 10 yrs) & 1.7 & $1.4-2.1$ & $<0.0001$ \\
\hline
\end{tabular}

${ }^{*}$ This is the result of a stepwise procedure. The variables considered in the model were: age (in 10 year units) and the 14 comorbidity variables except that 'diabetes (not listed as PRD)' was replaced by 'diabetes of either category' which included 'diabetes listed as PRD'

Table 4.11. Multivariate Cox proportional hazards model ${ }^{\star}$ for predictors of death within the first 90 days of starting RRT during 01/01/2005-30/09/2010: patients aged $\geqslant 65$ years

\begin{tabular}{lccc}
\hline Comorbidity & $\begin{array}{c}\text { Hazard } \\
\text { ratio }\end{array}$ & $95 \%$ CI & p value \\
\hline Ischaemic/neuropathic ulcers & 2.2 & $1.5-3.3$ & 0.0001 \\
MI in past 3 months & 2.0 & $1.4-2.9$ & 0.0003 \\
Malignancy & 1.7 & $1.4-2.1$ & $<0.0001$ \\
MI > 3 months ago & 1.6 & $1.2-2.0$ & 0.0002 \\
COPD & 1.6 & $1.2-2.1$ & 0.0006 \\
Age (per 10 yrs) & 1.5 & $1.3-1.7$ & $<0.0001$ \\
Angina & 1.4 & $1.1-1.8$ & 0.003 \\
CABG/angioplasty & 0.7 & $0.5-1.0$ & 0.04 \\
\hline
\end{tabular}

${ }^{*}$ This is the result of a stepwise procedure. The variables considered in the model were: age (in 10 year units), smoking and the 14 comorbidity variables except that 'diabetes (not listed as PRD)' was replaced by 'diabetes of either category' which included 'diabetes listed as PRD'

malignancy, liver disease and COPD) were among the eight variables independently associated with mortality beyond day 90 in patients $\geqslant 65$ years (tables 4.12 , 4.13). Diabetes mellitus was independently associated

Table 4.12. Multivariate Cox proportional hazards model ${ }^{\star}$ for predictors of death in the year after the first 90 days of starting RRT during 01/01/2005-30/09/2009: patients aged $<65$ years

\begin{tabular}{lccc}
\hline Comorbidity & $\begin{array}{c}\text { Hazard } \\
\text { ratio }\end{array}$ & 95\% CI & p value \\
\hline Malignancy & 3.1 & $2.3-4.2$ & $<0.0001$ \\
Ischaemic/neuropathic ulcers & 2.3 & $1.6-3.4$ & $<0.0001$ \\
Diabetes of either category & 1.7 & $1.4-2.2$ & $<0.0001$ \\
Liver disease & 1.6 & $1.1-2.5$ & 0.021 \\
COPD & 1.6 & $1.1-2.3$ & 0.024 \\
Age (per 10 yrs) & 1.4 & $1.2-1.5$ & $<0.0001$ \\
Smoking & 1.3 & $1.0-1.7$ & 0.047 \\
\hline
\end{tabular}

${ }^{*}$ This is the result of a stepwise procedure. The variables considered in the model were: age (in 10 year units) and the 14 comorbidity variables except that 'diabetes (not listed as PRD)' was replaced by 'diabetes of either category' which included 'diabetes listed as PRD'.
Table 4.13. Multivariate Cox proportional hazards model ${ }^{\star}$ for predictors of death in the year after the first 90 days of starting RRT during 01/01/2005-30/09/2009: patients aged $\geqslant 65$ years

\begin{tabular}{lccc}
\hline Comorbidity & $\begin{array}{c}\text { Hazard } \\
\text { ratio }\end{array}$ & $95 \%$ CI & p value \\
\hline Amputation & 2.0 & $1.3-3.1$ & 0.002 \\
Liver disease & 2.0 & $1.3-2.9$ & 0.001 \\
Malignancy & 1.8 & $1.6-2.1$ & $<0.0001$ \\
Age (per 10 yrs) & 1.7 & $1.6-1.9$ & $<0.0001$ \\
COPD & 1.5 & $1.2-1.8$ & $<0.0001$ \\
Cerebrovascular disease & 1.4 & $1.2-1.6$ & 0.0002 \\
Angina & 1.3 & $1.1-1.5$ & 0.005 \\
Claudication & 1.3 & $1.0-1.5$ & 0.04
\end{tabular}

${ }^{*}$ This is the result of a stepwise procedure. The variables considered in the model were: age (in 10 year units) and the 14 comorbidity variables except that 'diabetes (not listed as PRD)' was replaced by 'diabetes of either category' which included 'diabetes listed as PRD'

with increased mortality in patients $<65$ years but not in those aged $\geqslant 65$ years. Overall the final seven variables in the model exploring death in the year after the first 90 days of starting RRT in patients $<65$ years explain $30 \%$ of the variation in survival. For patients' $\geqslant 65$ years, only $14 \%$ of the variation in survival was explained by the eight variables included in the final model.

\section{Discussion}

Comorbidity data completeness has been a cause for concern since comorbidities were first reported by the UKRR in 1999 [11]. Overall the completeness of comorbidity reporting to the UKRR is fairly static. The current prevalence of comorbidity reporting of $49.3 \%$ in the UK compares with $85 \%$ in Canada, $95-100 \%$ in Australia and New Zealand and $100 \%$ in the US. Some work has recently been undertaken to learn from experience in these countries [12]. Missing data may hamper case-mix adjustment but also introduce the risk of selection bias, so caution must be used in interpreting the influence of comorbidity on patient outcomes. A recent study based on UKRR data suggested that patients with comorbidity recorded have significantly better health outcomes than those with missing comorbidity [6], so the findings from the selected group of patients reported in this chapter cannot be assumed to be representative of the whole dialysis population. Comorbidity information should improve in the future through a combination of linkage with other secondary 
data sources (e.g. Hospital Episode Statistics Dataset), statistical imputation techniques and local governance pressures, given that comorbidity items form part of the mandatory National Renal Dataset. In addition, ongoing efforts to understand the barriers to data capture and to optimise the processes utilised, involving all relevant stakeholders from individual clinicians, data managers, system suppliers and the UKRR team, are required to help improve the quality and completeness of this important information.

An interesting recurrent finding in several of the survival analyses is the lack of independent association of smoking or diabetes with mortality. This highlights the need for caution when interpreting the results of multivariable analyses in which co-variables are included in the model that may lie on the causal pathway. For example smoking and diabetes both contribute to vascular disease which may result in death. Therefore by including ischaemic heart disease or peripheral vascular disease in the model, the association between diabetes and smoking and mortality will be attenuated. The absence of an independent association should not however be interpreted as meaning smoking (for example) does not increase a dialysis patient's risk of death [13]. The observation that $13 \%$ of new RRT patients are recorded as current smokers remains a concern given the recognised substantial excess in cardiovascular risk that dialysis patients have compared with those with CKD or normal renal function $[14,15]$.

A further consideration is that even in analyses (both inside and outside the UK) with $100 \%$ comorbidity completeness, the proportion of variance in survival that can be explained by these major medical disorders generally remains below 50\% when age, primary renal disease, ethnicity and comorbidities are included in the statistical model. The UKRR is currently undertaking work exploring the associations between comorbidity and survival in greater detail. Future studies of survival should consider other factors such as nutrition, mobility, cognition and socio-economic status in addition to centre level factors at the start of dialysis to better assess the risk factors and outcomes for RRT patients.

Conflicts of interest: none

\section{References}

1 Ansell D, Roderick P, Hodsman A, Steenkamp R, Tomson C: Chapter 6: Survival of Incident and Prevalent patients; in Ansell D, Feehally J, Feest TG, Tomson C, Williams AJ, Warwick G: UK Renal Registry Report 2007, UK Renal Registry, Bristol, UK, 2007

2 Khan IH, Campbell MK, Cantarovich D, Catto GR, Delcroix C, Edward N, Fontenaille C, Fleming LW, Gerlag PG, van Hamersvelt HW, Henderson IS, Koene RA, Papadimitriou M, Ritz E, Russell IT, Stier E, Tsakiris D, MacLeod AM: Survival on renal replacement therapy in Europe: Is there a 'centre effect'? Nephrol Dial Transplant 1996;11:300-307

- 3 Hodsman A, Ben-Shlomo Y, Roderick P, Tomson CRV: The 'centre effect' in nephrology: What do differences between nephrology centres tell us about clinical performance in patient management? Nephron Clin Pract 2011;119:1: c10-c17

4 Marcelli D, Stannard D, Conte F, Held PJ, Locatelli F, Port FK: ESRD patient mortality with adjustment for comorbid conditions in Lombardy (Italy) versus the United States. Kidney Int 1996;50:10131018

5 Jager KJ, Zoccali C. Comorbidity data collection by renal registries - a remaining challenge. Nephrol Dial Transplant 2009;24: 2311-2313

-6 Collier T, Steenkamp R, Tomson C, Caskey F, Ansell D, Roderick P, Nitsch D: Patterns and effects if missing comorbidity data for patients starting renal replacement therapy in England, Wales and Northern Ireland. Nephrol Dial Transplant 2011;26:3651-3658

7 Ansell D, Tomson CRV: UK Renal Registry 11th Annual Report (December 2008): Chapter 15 The UK Renal Registry, UKRR database, validation and methodology. Nephron Clin Pract 2009;111(suppl 1): c277-c285
8 Office for National Statistics: The classification of ethnic groups (www.statistics.gov.uk). 2005

-9 Ford DJ, Fogarty DG, Steenkamp R, Tomson CR, Ben-Shlomo Y, Ansell D: UK Renal Registry 12th Annual Report (December 2009): Chapter 13: the UK Renal Registry advanced CKD study: frequency of incorrect reporting of date of start of RRT. Nephron Clin Pract 2010;115(suppl 1): c271-c278

10 Royston P, Sauerbrei W: A new measure of prognostic separation in survival data. Statistics in medicine 2004;23:723-748

11 Ansell D, Feest TG: Chapter 12: Co-morbidity of new patients: UK Renal Registry report 1999, UK Renal Registry, Bristol, UK, 1999

12 Karamadoukis L, Ansell D, Foley RN, McDonald SP, Tomson CRV, Trpeski L, Caskey FJ: Towards case-mix-adjusted international renal registry comparisons: How can we improve data collection practice? Nephrol Dial Transplant 2009;24:2306-2311

13 Caskey F, Webb L, Gilg J, Fogarty D: Chapter 6: Comorbidities and Current Smoking Status amongst Patients starting Renal Replacement Therapy in England, Wales and Northern Ireland from 2002-2008: national and centre-specific analyses. Nephron Clin Pract 2010; 115(suppl 1):c103-c116

14 Foley RN, Herzog CA, Collins AJ: Smoking and cardiovascular outcomes in dialysis patients: The United States Renal Data System Wave 2 study. Kidney Int 2003;63: 1462-1467

15 Zoccali C, Tripepi G, Mallamaci F: Predictors of cardiovascular death in ESRD. Semin Nephrol 2005;25:358-362 